\title{
Environmental conditions and serotype affect Listeria monocytogenes susceptibility to phage treatment in a laboratory cheese model
}

\author{
L. O. Henderson, ${ }^{1}$ L. A. Cabrera-Villamizar, ${ }^{1,2}$ J. Skeens, ${ }^{1}$ D. Kent, ${ }^{1}$ S. Murphy, ${ }^{1}$ M. Wiedmann, ${ }^{1}$ \\ and V. Guariglia-Oropeza ${ }^{1 *}$ \\ ${ }^{1}$ Department of Food Science, Cornell University, Ithaca, NY 14853 \\ ${ }^{2}$ Departamento de Ciencias Biológicas, Universidad de Los Andes, Bogotá, Colombia 111711
}

\section{ABSTRACT}

Listeria monocytogenes can survive and grow in a variety of environments, including refrigeration, making it difficult to control and highlighting the importance of optimizing control strategies against this pathogen. Listeria phages are attractive biocontrol agents because phages bind to specific wall teichoic acids (WTA) on the bacterial cell wall, inhibiting pathogens without disrupting the normal microbiota or structure of the food. Common stresses found on dairy products can affect cell wall composition and structure and subsequently affect the efficiency of control strategies that target the cell wall. The goal of this study was to determine the effect of a range of $\mathrm{pH}$ and temperatures on the effectiveness of a commercial phage cocktail treatment against several strains of $L$. monocytogenes in a cheese matrix. We developed a laboratory-scale cheese model that was made at different $\mathrm{pH}$, treated with phage, and then inoculated with L. monocytogenes. Cheeses were incubated at 6,14 , or $22^{\circ} \mathrm{C}$ for $14 \mathrm{~d}$, and bacterial counts were determined on $\mathrm{d} 1,7$, and 14 . Our data show that phage treatment has a limited ability to reduce $L$. monocytogenes counts at each temperature tested; however, it was more effective on specific strains of $L$. monocytogenes when cheese was stored at higher temperatures. More specifically, the average counts of $L$. monocytogenes on phage-treated cheese stored at $22^{\circ} \mathrm{C}$ were significantly lower than those on phage-treated cheese stored at 6 or $14^{\circ} \mathrm{C}$. Similarly, phage treatment was significantly more effective at inhibiting $L$. monocytogenes on cheese made at higher $\mathrm{pH}$ (6 and 6.5) compared with counts on cheese made at $\mathrm{pH} 5.5$, where L. monocytogenes did not grow. Furthermore, serotype was found to affect the susceptibility of L. monocytogenes to phage treatment; serotype $1 / 2$ strains showed significantly higher susceptibility to phage treatment

Received February 12, 2019.

Accepted July 2, 2019.

*Corresponding author: vg93@cornell.edu than serotype $4 \mathrm{~b}$ strains. Overall, our results suggest the importance of considering the efficacy of phage under conditions (i.e., temperature and $\mathrm{pH}$ ) specific to a given food matrix when applying interventions against this important foodborne pathogen.

Key words: bacteriophage, food safety, $\mathrm{pH}$, temperature

\section{INTRODUCTION}

Listeria monocytogenes is a gram-positive foodborne pathogen that can cause severe listeriosis in susceptible populations, such as immunocompromised individuals, pregnant women, newborns, and elderly adults (Jackson et al., 2018). This bacterium is the third leading cause of death related to foodborne illness in the United States (Barton Behravesh et al., 2011), and the Centers for Disease Control and Prevention (CDC) estimate that $L$. monocytogenes causes approximately 1,600 cases annually, including 260 deaths (Scallan et al., 2011; CDC, 2017). Listeria monocytogenes also causes disease in animals and can be isolated from both natural and food-processing environments (Nightingale et al., 2004).

Different serotypes of $L$. monocytogenes are associated with specific environments and disease cases (Orsi et al., 2011). The species consists of at least 4 lineages: I, II, III, and IV (Piffaretti et al., 1989; Rasmussen et al., 1995; Wiedmann et al., 1997; Roberts et al., 2006; Ward et al., 2008). Most L. monocytogenes isolates belong to lineages I and II, which contain serotypes more commonly associated with human clinical cases, including serotype $1 / 2 \mathrm{a}$ (lineage II) and serotypes $1 / 2 \mathrm{~b}$ and 4b (lineage I) (Orsi et al., 2011). Lineage II strains are common in food products, widespread in natural and farm environments, and are less frequently isolated from human clinical cases (Kabuki et al., 2004; Manfreda et al., 2005). Most human listeriosis outbreaks are associated with lineage I isolates (Jeffers et al., 2001). Lineage III and IV strains are rare and predominantly isolated from animal sources (Wiedmann et al., 1997; 
Jeffers et al., 2001) and therefore, were not included among the strains used in this study.

Contamination with $L$. monocytogenes is a concern in dairy processing environments based on its ability to grow in a wide range of temperatures $\left(0\right.$ to $\left.45^{\circ} \mathrm{C}\right)$, $\mathrm{pH}(4.4$ to 9.4$)$, and at high salt concentrations (13-14 wt/vol\%; Swaminathan et al., 2007). The ability of $L$. monocytogenes to rapidly adapt to changing environmental conditions enables it to survive harsh environments during food processing. Since 2006, the number of listeriosis outbreaks in the United States associated with cheese, two-thirds of which were Hispanic-style cheese, has increased (Jackson et al., 2018), which continues to raise concerns regarding $L$. monocytogenes contamination of fresh cheese and increases the need for precise intervention strategies. Soft-ripened or unripened cheese made from raw or improperly pasteurized milk is most commonly associated with disease outbreaks in cheese in the United States (Ibarra-Sánchez et al., 2017). Specifically, most dairy-associated foodborne outbreaks in the United States are linked to the Hispanic-style fresh cheese queso fresco (Ibarra-Sánchez et al., 2017). Hispanic-style fresh cheese is characterized by high water activity $\left(a_{\mathrm{w}}\right)$, low salt content, and near-neutral $\mathrm{pH}$, which creates an ideal environment for survival and growth of several foodborne pathogens (Leggett et al., 2012), specifically L. monocytogenes (Uhlich et al., 2006; Ibarra-Sánchez et al., 2017).

One possible strategy to prevent problems associated with L. monocytogenes contamination in food and foodprocessing environments is the use of lytic bacteriophages or phages (Mahony et al., 2011). Phage are the most abundant organisms on earth, can be isolated from various environments, including food, and are components of the human gut microbiota (Clokie et al., 2011). Lytic phages infect bacteria, resulting in lysis of the bacterial cell. Phages recognize and kill specific target bacteria; therefore, phage-based interventions can target specific foodborne pathogens without disrupting the normal and beneficial microflora of foods (Goodridge and Bisha, 2011). Several phage-based preparations have been approved for food applications in the United States and Europe, such as ListShield (Intralytix, Baltimore, MD), Listex P-100 (PhageGuard/Micreos, Wageningen, the Netherlands), EcoShield (Intralytix), SalmoFresh (Intralytix), and Salmonelex (PhageGuard). Although some studies have shown that these phage preparations can decrease L. monocytogenes (Silva et al., 2014; Perera et al., 2015), Escherichia coli (Carter et al., 2012), and Salmonella (Sharma et al., 2015) numbers on produce, dairy, and meat products, whether they can reduce pathogen prevalence or outbreak incidence remains to be determined. Furthermore, the efficacy of phage has been shown to vary in different food matrices and under different environmental conditions (Guenther et al., 2009).

Given the unique conditions encountered in cheese, the objective of this study was to investigate the effect of environmental conditions (e.g., temperature and $\mathrm{pH}$ ) on L. monocytogenes sensitivity to a commercial phage cocktail in a laboratory-scale cheese model. Effective and improved prevention of L. monocytogenes-related foodborne outbreaks and infections will require a thorough understanding of the effects of the environment on L. monocytogenes sensitivity to treatments to allow for appropriate development and application of control strategies.

\section{MATERIALS AND METHODS}

\section{Bacterial Strains and Growth Conditions}

We obtained 4 recent cheese outbreak strains that encompass the most common L. monocytogenes serotypes (4b, 1/2a and 1/2b; Table 1). Listeria monocytogenes strain 10403S (serotype 1/2a) was used as a reference in this study. For all experiments, strains were streaked from frozen brain heart infusion (BHI; Difco, Becton Dickinson and Co., Sparks, MD) stocks, stored at $-80^{\circ} \mathrm{C}$ in $15 \%$ glycerol, plated on a $\mathrm{BHI}$ agar plate, and then incubated at $37^{\circ} \mathrm{C}$ for $24 \mathrm{~h}$. A single colony was subsequently inoculated into $5 \mathrm{~mL}$ of $\mathrm{BHI}$ broth in $16-\mathrm{mm}$ tubes, followed by incubation at $37^{\circ} \mathrm{C}$ with shaking $(230 \mathrm{rpm}$ ) for $16 \mathrm{~h}$ (Series 25 Incubator, New Brunswick Scientific, Edison, NJ). After 16 h, $50 \mu \mathrm{L}$ of BHI culture was inoculated into $5 \mathrm{~mL}$ of fresh BHI broth and grown to an optical density (at $600 \mathrm{~nm}$ ) of 1.0 at $30^{\circ} \mathrm{C}$.

\section{Laboratory-Scale Cheese Model}

We modified the method described by Van Tassell et al. (2015) to make approximately 10-g miniature cheeses in 6-well plates. Briefly, using aseptic technique, 600 $\mathrm{mL}$ of pasteurized, nonhomogenized whole milk (Trinity Valley Dairy, purchased at retail in 1-gallon containers) was warmed to $35^{\circ} \mathrm{C}$. Then, $\mathrm{CaCl}_{2}$ (Dairy Connection Inc., Madison, WI) was added to milk to a final concentration of $1 \mathrm{mg} / \mathrm{mL}$ and the milk was combined with $6 \mathrm{~mL}$ of rennet solution $(90 \mu \mathrm{L}$ of double-strength vegetable rennet, CHY-Max; Chr. Hansen, Milwaukee, WI) diluted in $5,910 \mu \mathrm{L}$ of sterile water). To account for bacteria present and to ensure that no L. monocytogenes was in the milk before cheese was made, milk samples were plated on plate count agar (Difco, Becton Dickinson and Co.) and on L. monocytogenes plating 


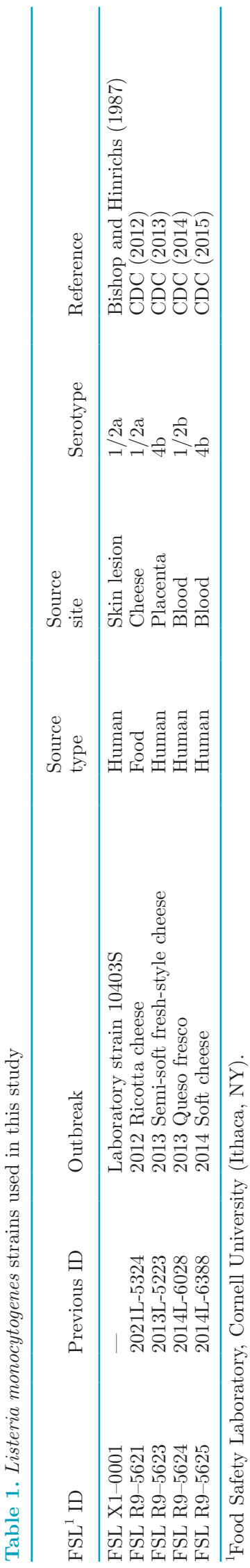

medium (Difco, Becton Dickinson and Co.). After 48 $\mathrm{h}$ of incubation at $32^{\circ} \mathrm{C}$ for plate count agar and 24 $\mathrm{h}$ of incubation at $30^{\circ} \mathrm{C}$ for L. monocytogenes plating medium, colonies were counted using a Q Count Colony Counter (Advanced Instruments, Norwood, MA).

To make cheese at different $\mathrm{pH}$, milk was acidified with the addition of vinegar (white, distilled) to reduce the $\mathrm{pH}$ from 6.5 to 6.0 or 5.5 before the addition of $\mathrm{CaCl}_{2}$ and rennet. Although acetic (vinegar), citric, and lactic acids are commonly used when making fresh cheese (Hnosko et al., 2008), the textural properties of queso blanco-type cheese were rated higher by consumers for cheese made with acetic acid (Farkye et al., 1995; Hnosko et al., 2008). To ensure that the desired $\mathrm{pH}$ was achieved, the $\mathrm{pH}$ of the milk was measured using a surface $\mathrm{pH}$ meter (Mettler Toledo, Columbus, $\mathrm{OH})$. The milk was then poured into "mini vats" and incubated at $35^{\circ} \mathrm{C}$ for $45 \mathrm{~min}$ in a water bath. The curds were cut using modified cheese harps. After cutting, curds were returned to the water bath and heated, and the temperature of the water bath was increased progressively until reaching $40^{\circ} \mathrm{C}(\sim 30 \mathrm{~min})$. Whey $(60$ $\mathrm{mL}$ ) was removed and replaced with $60 \mathrm{~mL}$ of $\mathrm{NaCl}$ solution $(0.16 \mathrm{~g} / \mathrm{mL})$. The curds were stirred gently with a plastic sterile loop and returned to the water bath for an additional 20 -min incubation at $40^{\circ} \mathrm{C}$. After incubation, the remaining whey was drained, and 15 $\mathrm{g}$ of curd was scooped into each well of a 6 -well plate. Plates were covered and pressed with $30-\mathrm{mm}$ caps for $2 \mathrm{~h}$ at room temperature. Cheese was subjected to analyses to determine $\mathrm{pH}$ and water activity (Aqualab Series 4TE, FF Instrumentation, Christchurch, New Zealand) throughout storage (Supplemental Table S1; https://doi.org/10.3168/jds.2019-16474). All samples were within the range of compositional values expected in commercial fresh cheese (Caro et al., 2014; Trmčić et al., 2017; Van Hekken et al., 2017; Holle et al., 2018).

\section{Growth of L. monocytogenes in the Cheese Model Containing a Commercial Listeria-Phage Cocktail}

Immediately after cheese was made, phage was applied to the surface of cheese by evenly pipetting 200 $\mu \mathrm{L}$ of ListShield (Intralytix, Baltimore, MD), a US Food and Drug Administration-approved commercial Listeria-phage cocktail, consisting of a mixture of equal proportions of 6 lytic bacteriophages, specifically effective against $L$. monocytogenes serotypes, to cover the surface of the $10 \mathrm{-g}$ cheese for a target final concentration of approximately $8 \times 10^{6}$ plaque-forming units (pfu) $/ \mathrm{g}$ or $9 \times 10^{6} \mathrm{pfu} / \mathrm{cm}^{2}$ (the dose recommended by the manufacturer is between 1 and $4 \mathrm{~mL} / \mathrm{lb}$. of a working stock that has been diluted to $1 \times 10^{9} \mathrm{pfu} / \mathrm{mL}$ ). Following $30 \mathrm{~min}$ of incubation at room temperature, 
each of the cheese samples was then surface-inoculated by spotting $100 \mu \mathrm{L}$ of 1 of the 5 selected L. monocytogenes strains at approximately $10^{5} \mathrm{cfu} / \mathrm{g}$, with an additional uninoculated cheese control. Plates with 6 cheeses per plate were covered and incubated at 6,14 , or $22^{\circ} \mathrm{C}$ for $14 \mathrm{~d}$, the typical shelf-life for a fresh cheese (Bermúdez-Aguirre and Barbosa-Canovas, 2010).

At 1,7 , or $14 \mathrm{~d}$ postinoculation, cheese was diluted $1 / 10$ with PBS and homogenized using a Stomacher (Seward, Worthing, UK). Homogenates were then serially diluted and plated on modified Oxford agar (Difco, Becton Dickinson and Co.) using an Autoplate spiral plating system (Advanced Instruments.) for L. monocytogenes quantification. After $48 \mathrm{~h}$ of incubation at $30^{\circ} \mathrm{C}$ (Curtis et al., 1989), colonies were counted using a Q Count Colony Counter (Advanced Instruments). Experiments were performed in at least biological triplicates.

\section{Statistical Analysis}

All statistical analyses were carried out in the $\mathrm{R}$ Statistical Programming Environment (R Core Team, 2015). We constructed individual linear mixed effects models for temperature and $\mathrm{pH}$ using the "lmer" function in the "lme4" package (Bates et al., 2015). For each model, the response was the number of $L$. monocytognes (log count; $\log \mathrm{cfu} / \mathrm{g}$ ) and random effects were (1) replicates and (2) plate nested within milk batch. Fixed effects were (1) temperature or $\mathrm{pH},(2)$ day of incubation, (3) presence or absence of phage, (4) strain, (5) age of the milk (based on a 21-d code date), and (6) the aerobic plate counts (log cfu/mL; bacterial counts in the milk before cheese was made). We also included the interactions phage $\times$ temperature or $\mathrm{pH}$, phage $\times$ strain, phage $\times$ day, and day $\times$ temperature or $\mathrm{pH}$. Post hoc pairwise comparisons of means were performed using "lsmeans" (Lenth, 2016). The cut-off for significance was set at $P<0.05$. Raw data and the $\mathrm{R}$ code used for statistical analyses are available on GitHub (https://github.com/lohenderson/ Phage_Listeria_Analysis_Model/).

\section{RESULTS}

\section{Temperature Affects Susceptibility of L. monocytogenes to Phage Treatment}

To assess the effect of different cheese incubation temperatures on the ability of phage to reduce $L$. monocytogenes loads on cheese, the commercial phage cocktail was added to the surface of cheese made at $\mathrm{pH}$ 6.5 from pasteurized milk before surface inoculation of
5 different L. monocytogenes strains. We did not detect L. monocytogenes in the milk or uninoculated controls (data not shown). Counts of L. monocytogenes numbers were quantified at d 1,7, and 14 for cheese incubated at 6,14 , or $22^{\circ} \mathrm{C}$ (Figure 1). A linear mixed effects model was used to specifically determine whether temperature, day of incubation, presence or absence of phage, and strain as well as interactions between temperature and presence of phage, temperature and day of incubation, and strain and presence of phage had significant effects on log-transformed bacterial numbers (Table 2). Figure 1 represents the actual observed data, and least squares means of estimated L. monocytogenes counts from the temperature model are shown across all strains in Figure 2 and calculated for each strain individually in Supplemental Figure S1 (https://doi.org/10.3168/ jds.2019-16474).

Presence of phage had a significant effect $(P<0.001)$ on $L$. monocytogenes counts with a model-estimated effect size of -1.34 (Table 2), indicating a 1.34 log lower count in the presence of phage. This result indicates that phage significantly reduced $L$. monocytogenes counts in the model cheese, as evident by the data in Figure 1; for cheese incubated at $6^{\circ} \mathrm{C}$, average $L$. monocytogenes counts (across strains and the 3 time points) were 6.33 and $7.13 \mathrm{log} \mathrm{cfu} / \mathrm{g}$ for cheese with and without phage, respectively. Phage-treated cheese had consistently lower L. monocytogenes counts at d 1 compared with untreated cheese $[0.76,1.39$, and $2.18 \mathrm{log} \mathrm{cfu} / \mathrm{g}$ lower average counts (across the 5 strains tested) for 6,14 , and $22^{\circ} \mathrm{C}$, respectively].

Not surprisingly, incubation day had significant effects on L. monocytogenes counts, with higher counts at $\mathrm{d} 7$ and 14 compared with d 1 (Table 2). The significance of day is not surprising considering that $L$. monocytogenes grew over time (average counts across strains were 4.85 and $7.57 \mathrm{log} \mathrm{cfu} / \mathrm{g}$ for $\mathrm{d} 1$ and 14 at $6^{\circ} \mathrm{C}$, respectively), consistent with previous observations that $L$. monocytogenes grows at refrigeration temperatures on soft cheeses at $\mathrm{pH}>5.9$ (Genigeorgis et al., 1991; Silva et al., 2014).

Importantly, we found a significant interaction effect $(P=0.006)$ between phage and storage at $22^{\circ} \mathrm{C}$ with an effect size -0.79 , indicating $0.79 \log$ lower L. monocytogenes counts relative to phage treatment at $6^{\circ} \mathrm{C}$. Although phage-treated cheeses had lower $L$. monocytogenes counts across temperatures, the difference between counts on treated and untreated cheese varied considerably by temperature; the smallest difference between phage-treated and untreated cheese for $\mathrm{d}$ $1(0.49 \log )$ was found for cheese incubated at $6^{\circ} \mathrm{C}$, with higher corresponding differences of 0.86 and $1.80 \mathrm{log}$ at 14 and $22^{\circ} \mathrm{C}$, respectively (Figure 1 ). Importantly, 


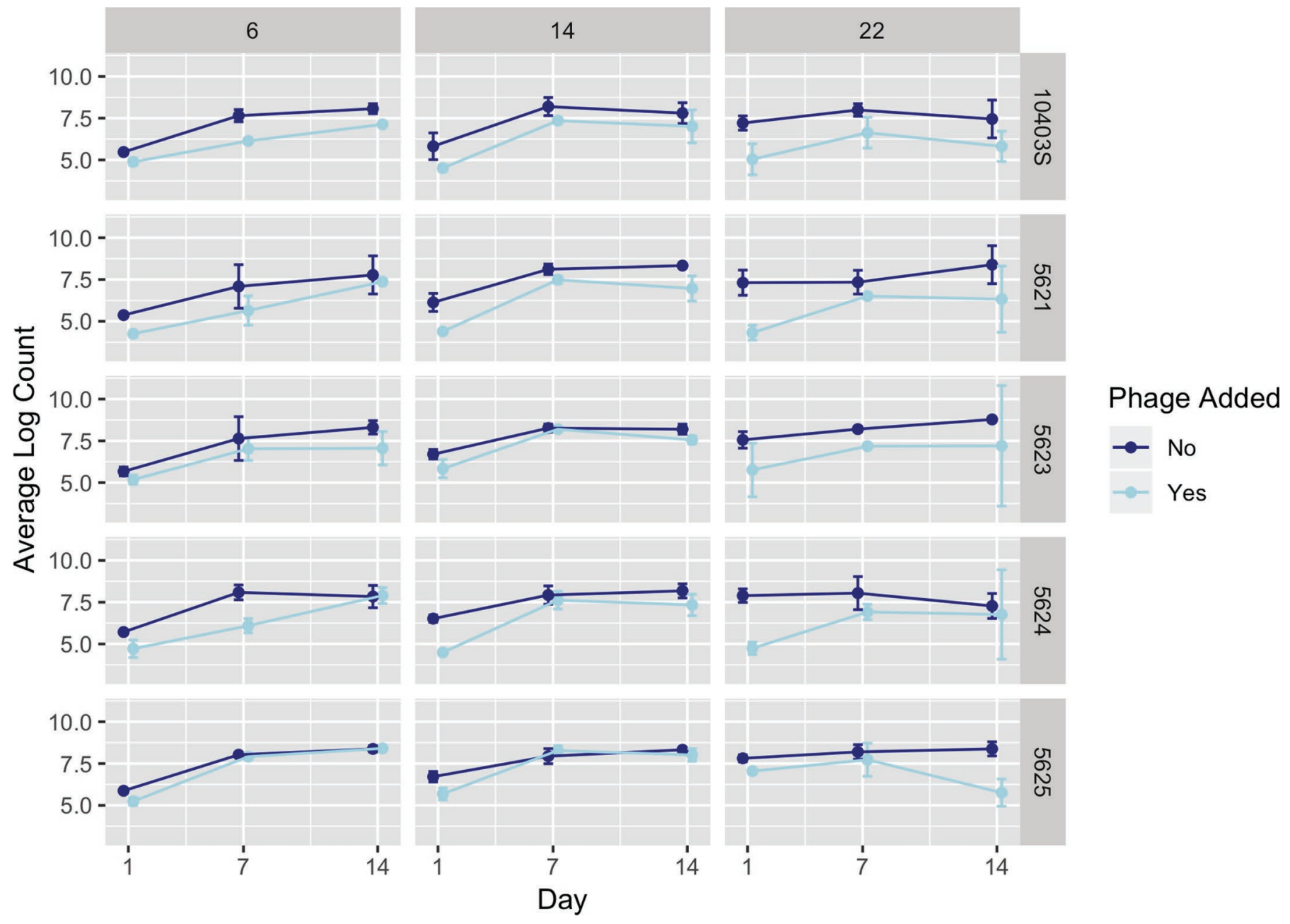

Figure 1. Average counts (log cfu/g) of Listeria monocytogenes in the presence (light blue) and absence (dark blue) of phage treatment in a laboratory-scale cheese model. Each cheese was inoculated with a single strain of L. monocytogenes (10403S, FSL R9-5621, FSL R9-5623, FSL R9-5624, or FSL R9-5625) to a level of approximately $5 \log \mathrm{cfu} / \mathrm{g}$. These results represent the effect of temperature $\left(6,14\right.$, and $\left.22^{\circ} \mathrm{C}\right)$ on the sensitivity of L. monocytogenes to a commercial phage cocktail. The data points are slightly offset such that the reader can clearly see each point; however, the points still correspond to 1, 7, and $14 \mathrm{~d}$. All values are the arithmetic mean of 3 independent experiments, and error bars denote standard errors. For some data points, error bars are not visible because the standard error was too low to yield a visible error bar. All cheeses were made at $\mathrm{pH}$ 6.5.

however, growth of L. monocytogenes was still observed in phage-treated cheese (Figure 1) where, for several strains, the difference between L. monocytogenes counts on phage-treated and untreated cheese was $<0.5 \log$ by d 7 and 14 . For example, at $14^{\circ} \mathrm{C}$, only strain $10403 \mathrm{~S}$ (both d 7 and 14) and strain 5621 (only d 14) showed $>0.5$ log differences between phage-treated and untreated cheese. Interestingly, at higher temperatures (14 and $22^{\circ} \mathrm{C}$ ), we found a few instances where d $14 \mathrm{~L}$. monocytogenes counts in phage-treated cheese were lower than d 7 counts; this pattern was most pronounced for the serotype 4b strain 5625 (Figure 1).

We found a significant interaction effect between presence of phage and strain 5625, one of the two serotype 4b strains used here $(P<0.001$; effect size of 0.68$)$, in- dicating that this strain showed 0.68 log higher counts in the presence of phage compared with the reference strain 10403S. For strain 5623, the other serotype 4b strain used here, the interaction effect between strain and temperature did not meet the $P<0.05$ cut-off $(P$ $=0.107)$ but showed the second highest positive effect size $(0.33)$ for the different strain $\times$ phage interaction analyses.

\section{pH Affects Susceptibility of L. monocytogenes to Phage Treatment}

To assess the effect of different $\mathrm{pH}$ on phage inhibition of $L$. monocytogenes counts, the commercial phage cocktail was added to the surface of cheeses made at $\mathrm{pH}$ 
Table 2. Model parameters for all fixed effects in the temperature model for Listeria monocytogenes counts

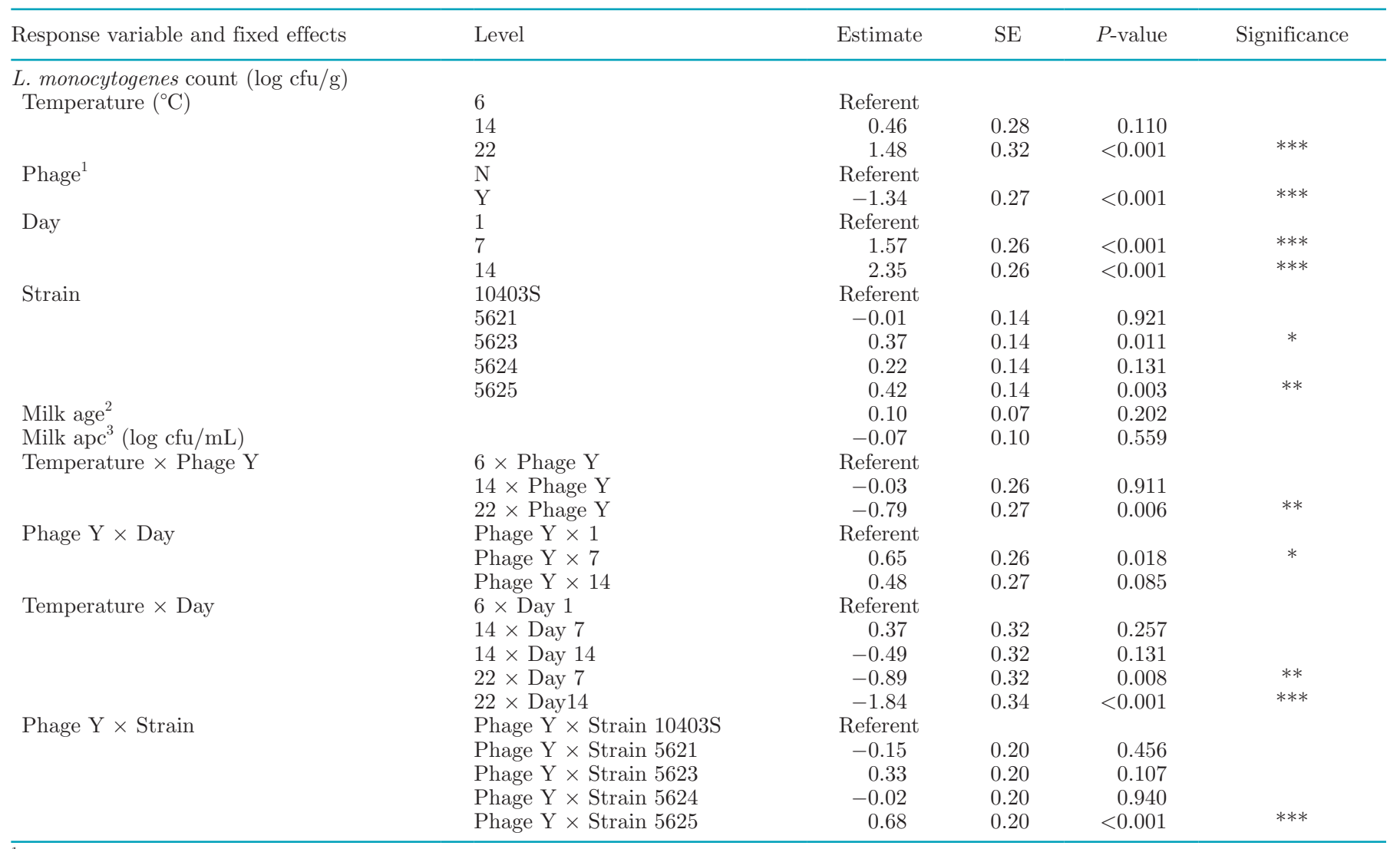

${ }^{1} \mathrm{~N}$ denotes the absence of phage; $\mathrm{Y}$ denotes the presence of phage.

${ }^{2}$ Age of milk when cheese was made, based on a 21 -d code date.

${ }^{3}$ Bacterial aerobic plate counts (apc; $\log \mathrm{cfu} / \mathrm{mL}$ ) in milk before cheese was made.

*** $P<0.001, * * P<0.01,{ }^{*} P<0.05$.

5.5, 6.0, and 6.5 before L. monocytogenes inoculation. The counts of L. monocytogenes were quantified after storage at $6^{\circ} \mathrm{C}$ for 1,7 , and $14 \mathrm{~d}$. A linear mixed effects model was used to determine whether $\mathrm{pH}$, day of incubation, presence or absence of phage, and strain, as well as interactions between $\mathrm{pH}$ and presence of phage and strain and presence of phage, and $\mathrm{pH}$ and day showed significant effects on log-transformed L. monocytogenes counts (Table 3). Data obtained (Figure 3) clearly show L. monocytogenes growth at $\mathrm{pH} 6.0$ and 6.5 , as well as a reduced effect of phage on $L$. monocytogenes counts at $\mathrm{pH} 5.5$, relative to that at $\mathrm{pH} 6.0$ and 6.5. Least squares means of estimated L. monocytogenes counts calculated from the $\mathrm{pH}$ model across strains (Figure 4) and for each strain individually (Supplemental Figure S2; https://doi.org/10.3168/jds.2019-16474) also showed no L. monocytogenes growth at $\mathrm{pH} 5.5$, regardless of treatment.

Presence of phage had a significant effect $(P<0.001)$ with an effect size of -1.00 , which indicates that $L$. monocytogenes counts were 1.00 log lower with phage treatment (Table 3). For cheese made at $\mathrm{pH}$ 6.0, average L. monocytogenes counts (across strains and time points) were 6.00 and $6.66 \mathrm{log} \mathrm{cfu} / \mathrm{g}$ for cheese with and without phage, respectively. The average observed L. monocytogenes counts across strains (Figure 4) also indicated that phage-treated cheese had consistently lower L. monocytogenes counts (4.58 to $7.48 \mathrm{log} \mathrm{cfu} / \mathrm{g}$ ) on all days compared with untreated cheese (4.97 to $7.86 \log \mathrm{cfu} / \mathrm{g})$. Although phage-treated cheese had lower L. monocytogenes counts across $\mathrm{pH}$, the difference between L. monocytogenes counts on treated and untreated cheese varied considerably by $\mathrm{pH}$; for example, the smallest difference between phage-treated and untreated cheese for d $1(0.23 \mathrm{log})$ was found for cheese made at $\mathrm{pH} 5.5$, with numerically higher corresponding differences of 0.28 and $0.63 \log$ for $\mathrm{pH} 6.0$ and 6.5 , respectively. Differences between L. monocytogenes counts on treated and untreated cheese made at $\mathrm{pH}$ 5.5 were minimal and ranged from 0.10 to $0.97 \mathrm{log}$, 

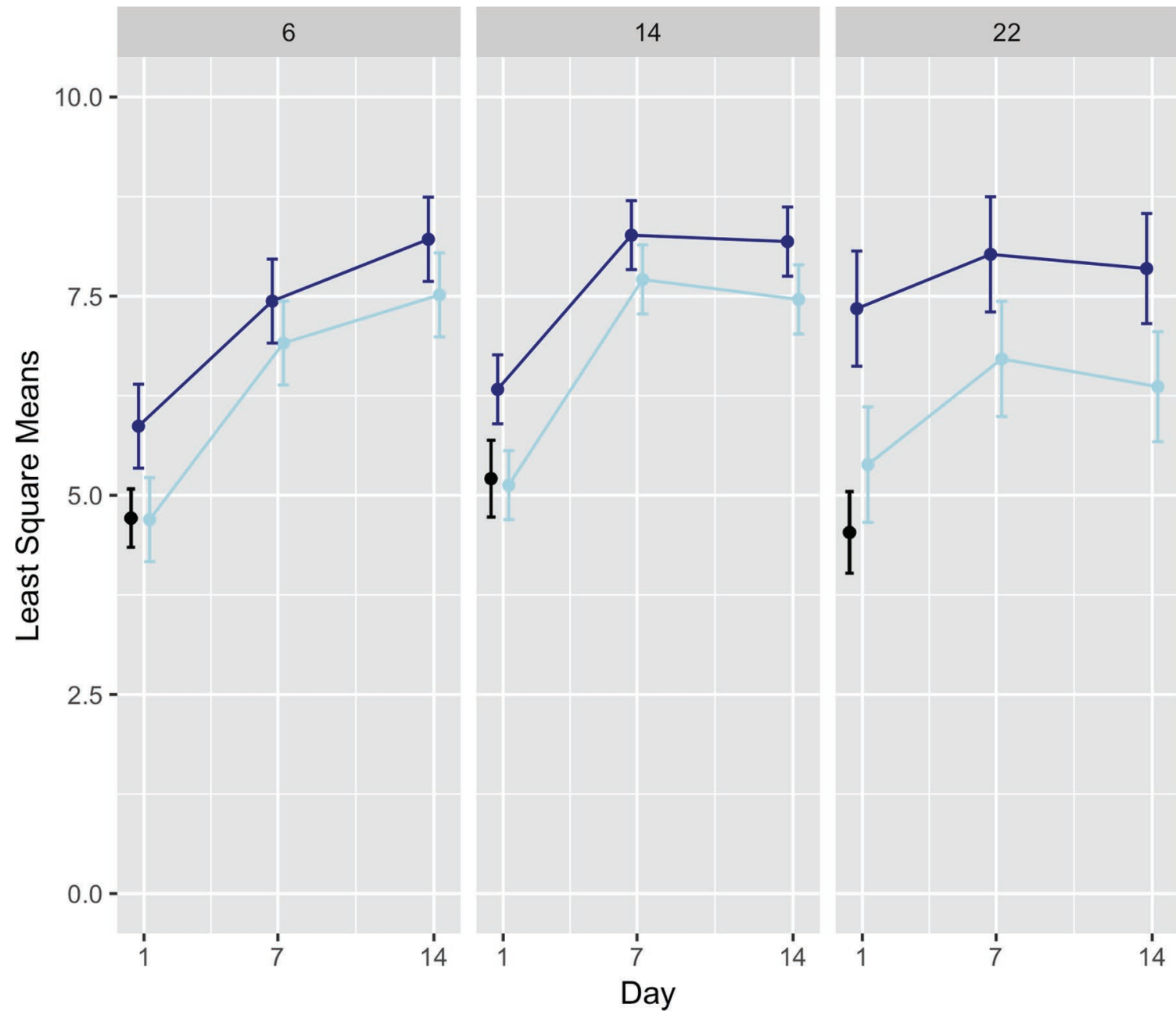

Phage Added

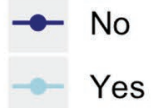

Figure 2. Least squares means of estimated numbers (log cfu/g) of Listeria monocytogenes calculated from the temperature model, based on data shown in Figure 1. Calculated initial (d 0) L. monocytogenes numbers based on the average inoculum level ( $\sim 5$ log cfu/g) are shown in black. Predicted numbers for cheese treated with phage are shown in light blue, and those for cheese without phage treatment are shown in dark blue. These results represent the predicted effect of temperature $\left(6,14\right.$, and $\left.22^{\circ} \mathrm{C}\right)$ on the sensitivity of L. monocytogenes to a commercial phage cocktail across strains (10403S, FSL R9-5621, FSL R9-5623, FSL R9-5624, and FSL R9-5625). The data points are slightly offset such that the reader can clearly see each point; however, the points still correspond to 1, 7, and 14 d. Error bars denote the $95 \%$ CI. All cheeses for these predictions were made at $\mathrm{pH} 6.5$.

compared with 0.15 to 1.38 and 0.11 to $2.00 \log$ for $\mathrm{pH}$ 6.0 and $\mathrm{pH} 6.5$, respectively (Figure 3 ).

Similar to data obtained from the temperature model, d 7 and 14 also had significant effects on $L$. monocytogenes numbers with higher numbers at both days compared with the reference (i.e., d 1; Table 3). Again, the significance of day is not surprising considering that L. monocytogenes showed growth over time for cheese formulated at $\mathrm{pH} 6.0$ and 6.5. For example, average counts across strains were 4.86 and $7.03 \mathrm{log}$ $\mathrm{cfu} / \mathrm{g}$ for $\mathrm{d} 1$ and 14, respectively, on cheese made at $\mathrm{pH}$ 6.0. Similar to the observations for $\mathrm{pH} 6.5$ cheese incubated at 6 and $14^{\circ} \mathrm{C}, \mathrm{pH} 6.0$ cheese incubated at $6^{\circ} \mathrm{C}$ also showed growth of L. monocytogenes for phage- treated cheese (Figure 3), with only an average $0.46 \log$ difference between phage-treated and untreated $\mathrm{pH} 6.0$ cheese at d 14 (Figure 4).

Finally, we found significant interaction effects between the presence of phage and strains 5623 and 5625, the two serotype $4 \mathrm{~b}$ strains used here $(P=0.011$; effect size of 0.43 and $P<0.001$; effect size 0.66 , respectively); this indicates that these strains showed 0.43 and 0.66 $\log \mathrm{cfu} / \mathrm{g}$ higher counts in the presence of phage compared with the reference strain 10403S. These findings are consistent with an initial plaque size screen of the 5 L. monocytogenes strains used here against the phage cocktail. Briefly, 2 independent replicates of a plaque assay on Luria Bertani medium buffered with $50 \mathrm{mM}$ 
Table 3. Model parameters for all fixed effects in the $\mathrm{pH}$ model for Listeria monocytogenes counts

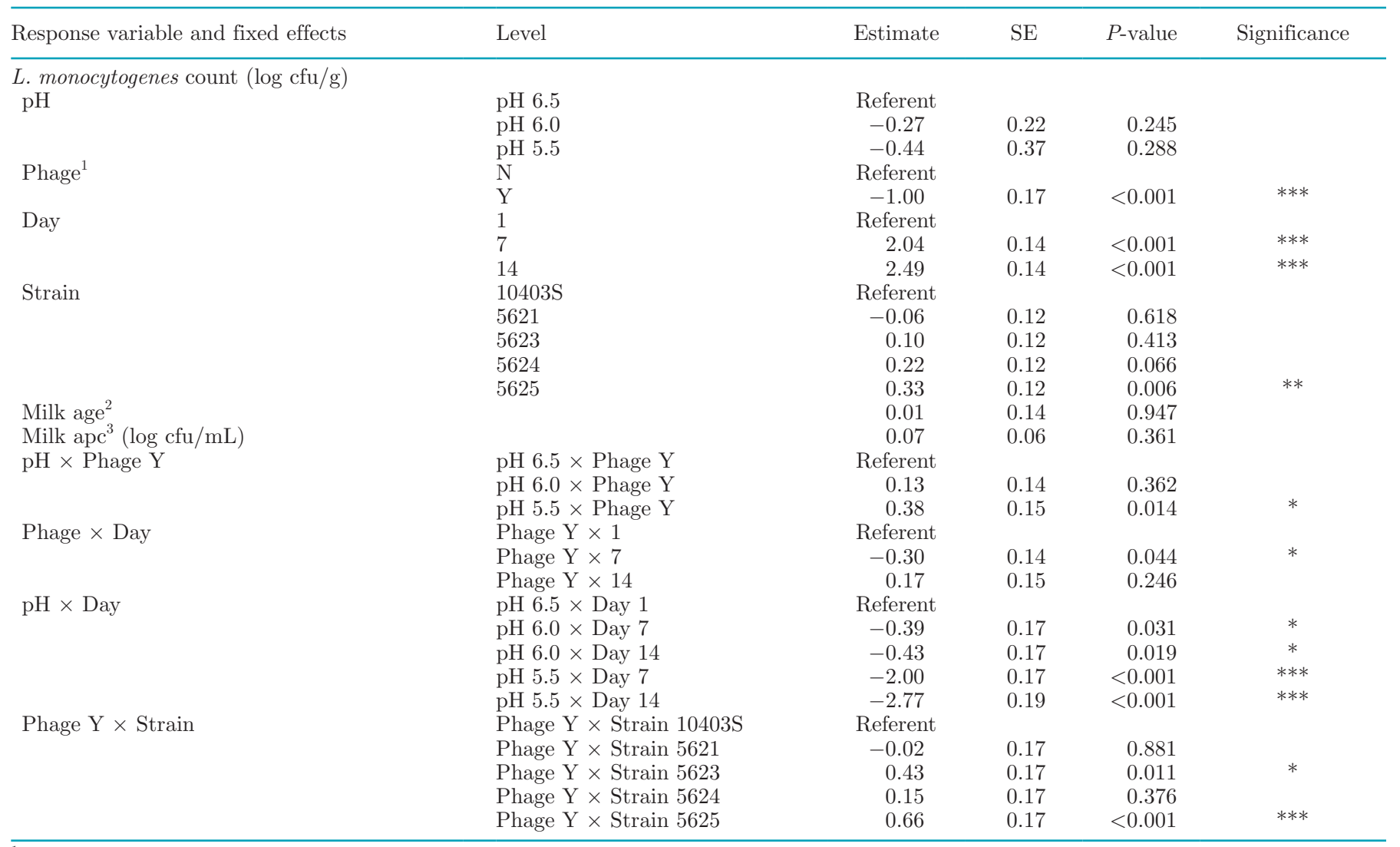

${ }^{1} \mathrm{~N}$ denotes the absence of phage; $\mathrm{Y}$ denotes the presence of phage.

${ }^{2}$ Age of milk when cheese was made, based on a 21 -d code date.

${ }^{3}$ Bacterial aerobic plate counts (apc; $\log \mathrm{cfu} / \mathrm{mL}$ ) in milk before cheese was made.

*** $P<0.001,{ }^{* *} P<0.01,{ }^{*} P<0.05$.

morpholinepropanesulfonic acid both showed weaker lysis of the 2 serotype $4 \mathrm{~b}$ strains compared with the 3 other strains (Supplemental Table S2; https://doi.org/ 10.3168/jds.2019-16474).

\section{DISCUSSION}

Although this study indicated that the commercial phage cocktail tested here, on average, reduced $L$. monocytogenes counts on cheese (with an overall effect size of around $1 \mathrm{log}$ ), we also showed that environmental conditions (especially temperature) and strain have significant effects on the efficacy of phage treatment in cheese. These findings have important implications as they (1) suggest that optimization of environmental conditions could be used to enhance the effectiveness of phage treatment, and (2) provide initial data that could be used in a formal risk assessment to quantify the effects of phage treatment with regard to reducing the risk of human listeriosis cases.

\section{Phage Reduction of L. monocytogenes}

Although our data support that phage can significantly decrease $L$. monocytogenes counts in cheese, we also found that the effectiveness of phage seemed to be enhanced when cheese was stored at higher temperatures, and that considerable L. monocytogenes growth can occur even in the presence of the phage cocktail. Our data showing considerable L. monocytogenes growth on cheese treated with phage are consistent with a study by Soni et al. (2012), who found that although surface treatment of queso fresco with phage P100 (7.7 log pfu/ $\mathrm{cm}^{2}$ ) led to an initial decrease (reduced to an undetectable limit, $<5 \mathrm{cfu} / \mathrm{cm}^{2}$ ) of $L$. monocytogenes on cheese stored at $4^{\circ} \mathrm{C}$, subsequent regrowth (back to inoculum level, approximately $4 \mathrm{log} \mathrm{cfu} / \mathrm{cm}^{2}$ ) of L. monocytogenes occurred by the end of $28 \mathrm{~d}$ of storage. Similarly, Silva et al. (2014) reported that when soft cheese was inoculated with approximately $10^{5} \mathrm{cfu} / \mathrm{g}$ of $L$. monocytogenes and treated with $8.3 \times 10^{7} \mathrm{pfu} / \mathrm{g}$ of phage 
$\mathrm{P} 100$, there was an initial $2 \mathrm{log}$ reduction (at $30 \mathrm{~min}$ after treatment); however, after $7 \mathrm{~d}$ of storage at $10^{\circ} \mathrm{C}$, they found only a $\sim 1 \log$ reduction of $L$. monocytogenes numbers on phage-treated cheese compared with untreated controls. Studies in tryptic soy broth also showed regrowth of $L$. monocytogenes after 2 wk, even though phage treatment at $2 \times 10^{9}$ or $2 \times 10^{10} \mathrm{pfu} /$ $\mathrm{mL}$ resulted in a 4 to $7 \mathrm{log}$ reduction at different temperatures $\left(4,10\right.$, and $20^{\circ} \mathrm{C}$ ) within the first 2 wk (Fister et al., 2016). Conversely, Carlton et al. (2005) reported complete eradication (below detection limit) and therefore no regrowth of $L$. monocytogenes on a ripened soft cheese stored at $14^{\circ} \mathrm{C}$ when the washing solution was inoculated with $2 \times 10^{1} \mathrm{cfu} / \mathrm{cm}^{2}$ L. monocytogenes at the beginning of the ripening period, and $2 \times 10^{6} \mathrm{pfu} /$ $\mathrm{cm}^{2}$ P100 was subsequently applied to the washing/ smearing solution during the rind washings (Carlton et al., 2005). The observation that our data did not show an initial reduction of the magnitude observed in the Soni et al. (2012) and Silva et al. (2014) studies or the undetectable level of L. monocytogenes reported by Carlton et al. (2005) could be due to differences in experimental set-up. For example, Silva et al. (2014) inoculated the cheese and homogenized the sample before phage treatment, which could increase the efficacy of phage treatment.

Overall, our data, as well as some previous data, indicate the potential for regrowth of $L$. monocytogenes

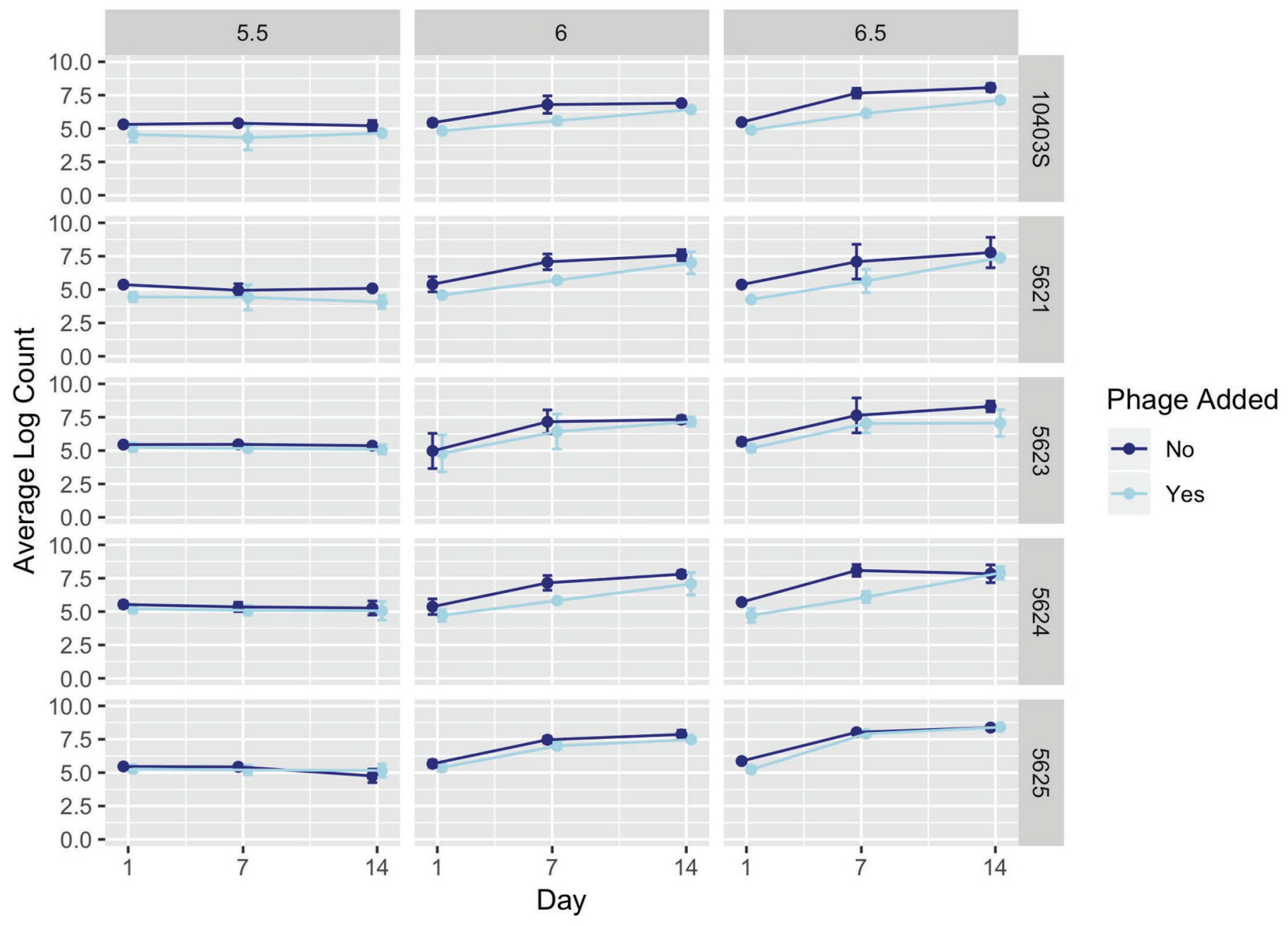

Figure 3. Average counts (log cfu/g) of Listeria monocytogenes in the presence (light blue) and absence (dark blue) of phage treatment in a laboratory-scale cheese model. Each cheese was inoculated with a single strain of L. monocytogenes (10403S, FSL R9-5621, FSL R9-5623, FSL R9-5624, or FSL R9-5625) to a level of approximately $5 \mathrm{log} \mathrm{cfu} / \mathrm{g}$. These results represent the effect of $\mathrm{pH}(5.5,6.0$, and 6.5$)$ on the sensitivity of L. monocytogenes to a commercial phage cocktail. The data points are slightly offset such that the reader can clearly see each point; however, the points still correspond to 1, 7, and $14 \mathrm{~d}$. All values are the arithmetic mean of 3 independent experiments, and error bars denote standard errors. For some data points, error bars are not visible because the standard error was too low to yield a visible error bar. All cheeses for these predictions were stored at $6^{\circ} \mathrm{C}$. 

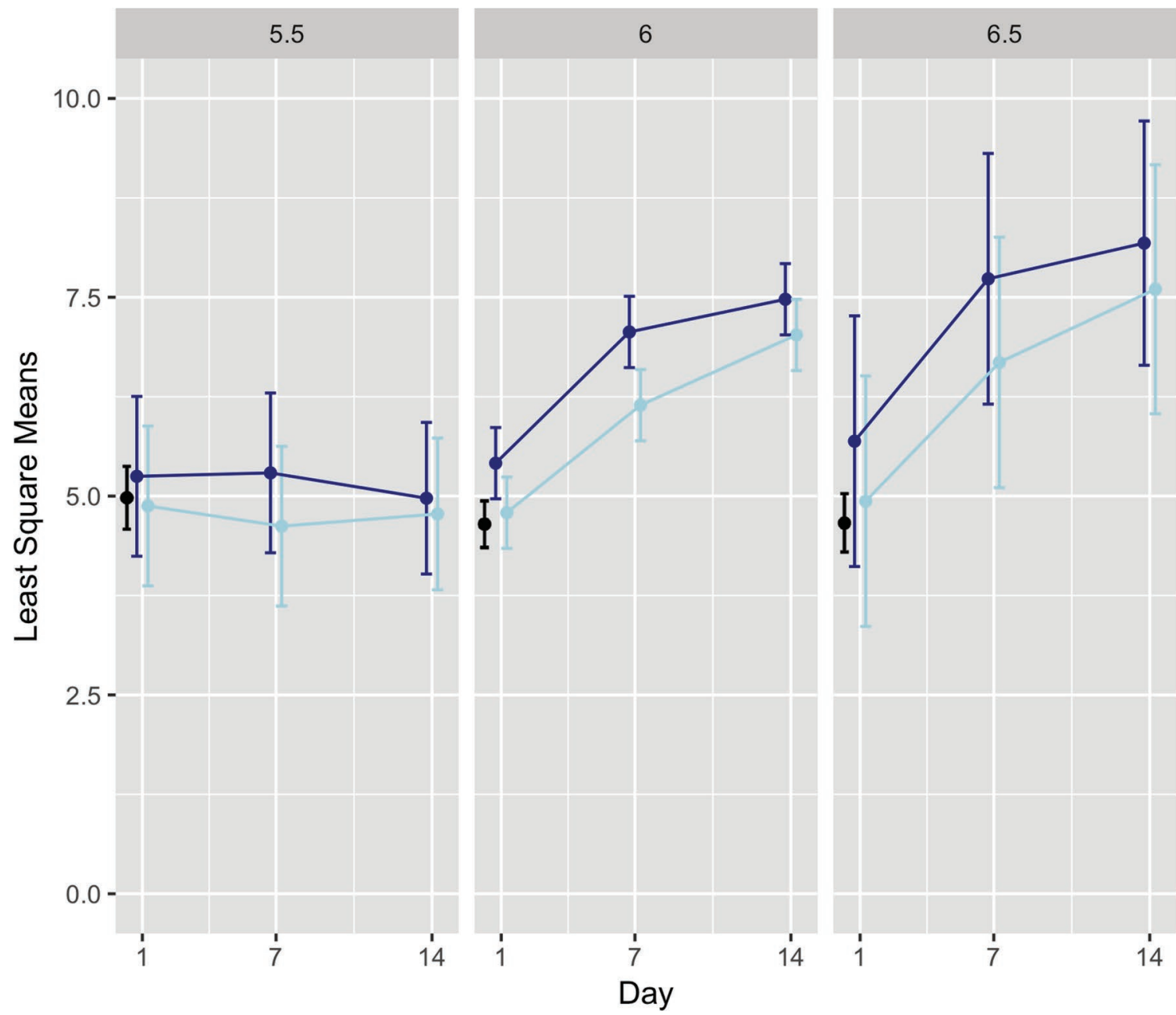

Phage Added

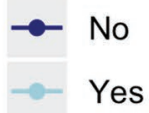

Figure 4. Least squares means of estimated Listeria monocytogenes numbers (log cfu/g) calculated from the $\mathrm{pH}$ model, which is based on data shown in Figure 3. Calculated initial (d 0) L. monocytogenes numbers based on the average inoculum level ( $\sim 5$ log cfu/g) are shown in black. Predicted numbers for cheese treated with phage are shown in light blue, and those for cheese without phage treatment are shown in dark blue. These results represent the predicted effect of $\mathrm{pH}(5.5,6.0$, and 6.5$)$ on the sensitivity of L. monocytogenes to a commercial phage cocktail across strains (10403S, FSL R9-5621, FSL R9-5623, FSL R9-5624, and FSL R9-5625). The data points are slightly offset such that the reader can clearly see each point; however, the points still correspond to 1, 7, and 14 d. Error bars denote the $95 \%$ CI. All cheeses for these predictions were stored at $6^{\circ} \mathrm{C}$.

during long-term storage, even when phage treatment results in an initial L. monocytogenes reduction. Hence, studies over product shelf life are essential to appropriately evaluate the effectiveness of phage treatment; use of these data in risk assessments (which would consider, among other parameters, storage time before consumption) can then provide a more accurate assessment of the public health impact of phage applications. Several factors might explain the regrowth of $L$. monocytogenes after initial significant reduction, including, but not limited to, (1) emergence and subsequent growth of phage resistant mutants (e.g., as reported by Denes et al., 2015); (2) transient resistance of L. monocytogenes to phage cocktail; and (3) degradation of phage or binding of phage to food matrix components, inhibiting the ability of phage to infect $L$. monocytogenes.

Importantly, while we specifically found a significant interaction effect between phage treatment and cheese incubation at $22^{\circ} \mathrm{C}$, storage or incubation at this temperature is neither feasible nor realistic for Hispanicstyle fresh cheese because it can allow growth of molds and other spoilage or pathogenic microorganisms, which could reduce L. monocytogenes numbers due to competition. Consistent with our findings, Lee et al. (2017) reported that $10^{6}$ to $10^{7} \mathrm{pfu} / \mathrm{mL}$ of lytic phage (LMP7) inhibited L. monocytogenes growth in skim milk stored at 4,10 , and $30^{\circ} \mathrm{C}$; however, phage treatment was most effective at $30^{\circ} \mathrm{C}$, resulting in a nearly $1 \log$ difference 
between treated and untreated skim milk after $1 \mathrm{~d}$ compared with a $<0.5 \log$ difference at $10^{\circ} \mathrm{C}$ (Lee et al., 2017). Preliminary evidence for enhanced effectiveness of phage in foods incubated at higher temperatures has also been reported for nondairy foods. For example, Guenther and Loessner (2011) showed that Listeria phage A511 was able to reduce L. monocytogenes numbers on hot dogs, chocolate milk, and cabbage by 2.3 to $5 \mathrm{log} \mathrm{cfu} / \mathrm{cm}^{2}$ when stored at $6^{\circ} \mathrm{C}$ compared with untreated controls; at $20^{\circ} \mathrm{C}$, phage was able to reduce L. monocytogenes numbers by 3.8 to $6.4 \log \mathrm{cfu} / \mathrm{cm}^{2}$.

Previous studies have shown that native bacteria present in the milk can grow on cheese, especially when stored at higher temperatures (Ostergaard et al., 2014; Tirloni et al., 2019) and subsequently outcompete Listeria, resulting in limited L. monocytogenes growth (Guillier et al., 2008; Mounier et al., 2008; Dalgaard and Mejlholm, 2019). However, our data show similar L. monocytogenes numbers at all temperatures in untreated cheese (Figures 1 and 2), suggesting that the enhanced effectiveness of phage-mediated L. monocytogenes reduction at higher temperatures is due to temperature affecting the phage-Listeria interaction and not due to an effect of the native bacteria on Listeria. Other possible explanations for greater phage-mediated L. monocytogenes reductions at higher temperatures include (1) enhanced sensitivity of metabolically more active $L$. monocytogenes, and (2) enhanced expression of phage receptors in L. monocytogenes grown at $22^{\circ} \mathrm{C}$ compared with lower temperatures (such as $6^{\circ} \mathrm{C}$ ). Several studies have indicated that metabolically active bacteria are more effectively killed by phage (ChibaniChennoufi et al., 2004; Clokie et al., 2011; Denes and Wiedmann, 2014). Prior studies have theorized that metabolically active bacteria are required for successful use of phage because these control strategies rely on host cell metabolism for phage replication and consequently bacterial cell lysis, leading to the release of progeny phage. Specific studies supporting this theory include a study by Fister et al. (2016), which found that conditions that reduced metabolism and growth rate of the host cell decreased the effectiveness of phage treatment. Previous studies also support that temperature can affect the physiological state of $L$. monocytogenes in a way that enhances the accessibility of phage receptors on the host. For example, previous studies have shown that phage adsorption of P100-like Listeria phage is more efficient at $30^{\circ} \mathrm{C}$ than at $37^{\circ} \mathrm{C}$, potentially because of more accessible WTA receptors (Denes et al., 2015; Tokman et al., 2016). Finally, temperatures (and other environmental conditions) facilitating more rapid growth of L. monocytogenes will lead to larger L. monocytogenes populations, which will enhance the likelihood of phage-bacteria contact and lead to faster phage propagation, further enhancing the effectiveness of phage treatment. This mechanism could, in particular, contribute to the enhanced die-off seen here in at least one strain at d 14 .

\section{Effectiveness of Phage}

Although our data indicate that $\mathrm{pH}$ can play a role in the effectiveness of phage treatment, the predominant effect of $\mathrm{pH}$ observed here was a lack of $L$. monocytogenes growth on the laboratory-scale cheese formulated at $\mathrm{pH} 5.5$, along with a reduced ability of phage to kill $L$. monocytogenes in cheese at that $\mathrm{pH}$. The lack of $L$. monocytogenes growth at $\mathrm{pH} 5.5$ is consistent with results from Genigeorgis et al. (1991), who reported that growth of $L$. monocytogenes was supported on various cheese types, characterized by higher $\mathrm{pH}$ (5.9 to 7.7), whereas cheese with low $\mathrm{pH}$ (4.9 to 5.7) did not support L. monocytogenes growth. Similarly, Guenther and Loessner (2011) reported that L. monocytogenes grew better on cheese when the $\mathrm{pH}$ increased above 6.0. Others have also shown that the acidity of the environment affects the efficiency of phage infection or the success of phage treatment. For example, Langlet et al. (2007) observed that phage MS2 formed 1.1 and $3.0 \log \mathrm{pfu} /$ $\mathrm{mL}$ fewer plaques on plaquing medium at $\mathrm{pH} 3.9$ and 2.5, respectively, compared with plaquing medium at $\mathrm{pH}$ 6.7. Additionally, studies on different low-pH food matrices, such as hard cheese or apples, have reported little to no L. monocytogenes reduction in the presence of phage. For example, Perera et al. (2015) reported a $0.7 \log$ reduction of $L$. monocytogenes when hard cheese (typically $\mathrm{pH} 5.1-5.4$ ) samples were treated with $1 \times$ $10^{8} \mathrm{pfu} / \mathrm{g}$ of a commercial phage cocktail, whereas Silva et al. (2014) reported a $2 \log$ reduction of L. monocytogenes on soft cheese (typically $\mathrm{pH}$ 6.2-6.5) treated with $8.3 \times 10^{7} \mathrm{pfu} / \mathrm{g}$ of phage P100. Furthermore, Oliveira et al. (2014) reported no significant difference in L. monocytogenes counts between control and phagetreated samples of fresh-cut apple slices ( $\mathrm{pH} 3.76)$.

Importantly, our data confirm that the effectiveness of phage seems to be enhanced when cheese is made at a higher $\mathrm{pH}$. Although we did not find a significant effect at $\mathrm{pH} 6.0$ (relative to $\mathrm{pH} 6.5$ ), cheese formulated at $\mathrm{pH} 6.0$ showed the greatest phage-mediated reduction of $L$. monocytogenes numbers compared with untreated cheese. However, as observed with temperature, $L$. monocytogenes is still able to grow in the presence of the phage cocktail. Consistent with our findings, Silva et al. (2014) reported that in 2 types of Brazilian soft cheese, which have near neutral $\mathrm{pH}$, bacteriophage P100 (applied at approximately $10^{7} \mathrm{pfu} / \mathrm{g}$ ) initially 
reduced L. monocytogenes counts by approximately 2 log compared with the untreated control at $30 \mathrm{~min}$ postinfection; however, the difference between treated and untreated was only $1 \log$ after $7 \mathrm{~d}$ of storage. Guenther and Loessner (2011) also found that Listeria phage A511(approximately $10^{8} \mathrm{pfu} / \mathrm{cm}^{2}$ ) was able to reduce $L$. monocytogenes inoculum levels below detectable levels (approximately $10^{3} \mathrm{cfu} / \mathrm{cm}^{2}$ ) in cheese that had a $\mathrm{pH}$ of 7.6 after ripening.

Possible explanations for the enhanced effectiveness of phage-mediated $L$. monocytogenes reduction at higher $\mathrm{pH}$ (Figure 4) include (1) enhanced phage attachment to the host, and (2) increased sensitivity of $L$. monocytogenes not grown under multiple stress conditions. Reduced phage stability would also result in a decrease of overall efficacy of phage treatment; however, prior data suggest that reduced phage stability at the lower $\mathrm{pH}$ used here is not an issue; Fister et al. (2016) reported that phage P100 was stable when incubated in tryptic soy broth adjusted to a $\mathrm{pH}$ range of 4 to 10 , and phage P100 numbers decreased by less than $0.5 \log \mathrm{pfu} / \mathrm{mL}$ after $24 \mathrm{~h}$ and between 1 to $2 \log$ $\mathrm{pfu} / \mathrm{mL}$ after $1 \mathrm{mo}$, respectively. These data suggest that phage is stable under the $\mathrm{pH}$ conditions tested in our study and that the phage cocktail is likely able to remain effective over the shelf life of cheese. Besides phage stability, attachment of the phage to its bacterial host is essential to the success of phage treatment and can be affected by $\mathrm{pH}$. Previous studies suggest that environmental factors can change L. monocytogenes cell envelope physiology, influencing the effectiveness of cell envelope-acting bactericidal treatments (Cotter and Hill, 2003). For example, a previous study showed that low $\mathrm{pH}$ changes the cell membrane composition, leading to tolerance of Listeria to other antilisterial compounds such as the cationic antimicrobial nisin (Verheul et al., 1997). Thus, we could hypothesize that a similar mechanism could contribute to an enhanced effect of phage (which also binds to cell envelope components) at higher $\mathrm{pH}$.

\section{L. monocytogenes Serotype Affects Efficiency of the Phage Cocktail}

In addition to the effects of environmental conditions, our data also indicate that serotype $4 \mathrm{~b}$ strains had reduced sensitivity to the phage cocktail used, across $\mathrm{pH}$ and temperature conditions tested. These findings are consistent with a considerable body of work indicating that the host range of Listeria phage corresponds to host serotype (Wendlinger et al., 1996; Kim et al., 2008; Vongkamjan et al., 2012). Differences among $L$. monocytogenes serotypes can be attributed to the composition of their WTA, cell surface polysaccharides. For example, serotype $1 / 2$ strains have terminal rhamnose and $\mathrm{N}$-acetylglucosamine (GlcNAc) residues, whereas 4b strains are decorated with terminal glucose and galactose residues (Eugster et al., 2015). As an example of Listeria-phage host specificity patterns, Wendlinger et al. (1996) reported that Listeria-phage A118, a temperate Siphovirus, attacks 1/2 serotypes, and Siphoviral phage A500 primarily lyses serotype 4b, whereas the broad-host-range Myovirus phage A511 lyses most $L$. monocytogenes strains. Importantly, however, a putative CRISPR system has been identified in Listeria, which might defend against bacteriophage infection. Although locus I is conserved in both serotype $1 / 2 \mathrm{a}$ and $4 \mathrm{~b}$ strains, locus II is only present in $4 \mathrm{~b}$ strains. Furthermore, only locus II seems to be functional (Klumpp and Loessner, 2013). Although the phage cocktail used in this study included both Siphoviridae and Myoviridae phage, which should have a broad host range against $L$. monocytogenes serotypes, our data suggest that at least some phage in this cocktail could have reduced or limited ability to lyse either serotype $4 \mathrm{~b}$ strains in general or the specific serotype $4 \mathrm{~b}$ strains included here. Our findings are also consistent with a previous study indicating that at least some wild-type L. monocytogenes strains might be resistant to commercially used phage cocktails (Vongkamjan et al., 2012). In addition, or alternatively, the serotype $4 \mathrm{~b}$ strains tested here might have a specific ability to adapt to the Hispanic-style fresh cheese environments, making them less susceptible to phage treatment in this food matrix. Overall, our findings, along with previous studies, support the importance of validating phage-based treatment strategies with both L. monocytogenes serotypes and environmental conditions relevant to a given application.

Our data suggest that $\mathrm{pH}$, temperature, and serotype influence the effectiveness of phage treatment against L. monocytogenes in a laboratory-scale cheese model; however, the overall phage-dependent reduction was limited. Additionally, except for cheese made at pH 5.5, all treated samples allowed growth of L. monocytogenes after a 14-d incubation. Our results highlight a need for fine-tuning control strategies against L. monocytogenes. In comparison, the bacteriocin nisin can be added to cheese to control for L. monocytogenes, and it has been proven to reduce numbers in a dose-dependent way (Van Tassell et al., 2015). Whether environmental conditions affect the effectiveness of nisin treatment in cheese is the focus of our follow-up study. In addition to nisin, plant extracts such as ferulic acid have been used to inhibit the growth of $L$. monocytogenes on cheese, with some success (Van Tassell et al., 2015). Importantly, $L$. monocytogenes seems less likely to develop resistance to ferulic acid (Takahashi et al., 2015) than to nisin or 
phage; therefore, a combined treatment approach could be an appropriate strategy to reduce $L$. monocytogenes numbers in a food matrix and decrease the likelihood of resistance, which could be effective regardless of environmental factors.

\section{CONCLUSIONS}

Overall, our data suggest that phage-based control strategies can reduce L. monocytogenes populations in cheese, and that the effectiveness of these strategies is affected by $L$. monocytogenes strains and environmental conditions. Challenge studies, typically conducted by industry, provide only limited insights on the actual value of using phage-based control strategies either for public health or for an individual business that wants to reduce the risk of an outbreak or a recall associated with its products. Further work is needed to develop a formal risk assessment that can be used to predict the actual benefits of using phage-based control strategies to not only reduce the risk of contamination, but also decrease the number of human listeriosis cases, taking into account the expected distributions of storage temperatures and times between production and consumption, as well as the likelihood of contamination with different strain and serotypes. This is important because our data suggest that phage-based control strategies could have limited effect on reducing public health risks if, for example, cheese made at $\mathrm{pH} 6.5$ is typically stored at $6^{\circ} \mathrm{C}$ or below and consumed after 14 d. In contrast, phage treatment could be substantial if cheese is typically stored at higher temperatures and consumed within a few days after production.

\section{ACKNOWLEDGMENTS}

This work was made possible by the research funding provided by the National Dairy Council and administered by Dairy Research Institute (Rosemont, IL). The authors thank Aljosa Trmcic (British Columbia Centre for Disease Control, Vancouver, Canada) for help developing the laboratory-scale cheese protocol and Erika Mudrak (Cornell Statistical Consulting Unit, Cornell University, Ithaca, NY) for help with experimental design and statistical consulting. The authors thank the Centers for Disease Control and Prevention (CDC; Atlanta, GA) for providing L. monocytogenes strains associated with recent cheese outbreaks.

\section{REFERENCES}

Barton Behravesh, C., T. F. Jones, D. J. Vugia, C. Long, R. Marcus, K. Smith, S. Thomas, S. Zansky, K. E. Fullerton, O. L. Henao, E. Scallan, and F. W. Grp. 2011. Deaths associated with bacterial pathogens transmitted commonly through food: Foodborne diseases active surveillance network (FoodNet), 1996-2005. J. Infect. Dis. 204:263-267.

Bates, D., M. Machler, B. M. Bolker, and S. C. Walker. 2015. Fitting linear mixed-effects models using lme4. J. Stat. Softw. 67:1-48.

Bermúdez-Aguirre, D., and G. V. Barbosa-Canovas. 2010. Processing of soft Hispanic cheese ("queso fresco") using thermo-sonicated milk: A study of physiochemical characteristics of storage life. J. Food Sci. 75:S548-S558.

Bishop, D. K., and D. J. Hinrichs. 1987. Adoptive transfer of immunity to Listeria monocytogenes. The influence of in vitro stimulation on lymphocyte subset requirements. J. Immunol. 139:2005-2009.

Carlton, R. M., W. H. Noordman, B. Biswas, E. D. de Meester, and M. J. Loessner. 2005. Bacteriophage P100 for control of Listeria monocytogenes in foods: Genome sequence, bioinformatic analyses, oral toxicity study, and application. Regul. Toxicol. Pharmacol. 43:301-312.

Caro, I., S. Soto, L. Fuentes, N. Gutirrez-Mendez, B. Garcia-Islas, K. E. Monroy-Gayosso, and J. Mateo. 2014. Compositional, functional and sensory characteristics of selected Mexican cheeses. Food Nutr. Sci. 5:366-375.

Carter, C. D., A. Parks, T. Abuladze, M. Li, J. Woolston, J. Magnone, A. Senecal, A. M. Kropinski, and A. Sulakvelidze. 2012. Bacteriophage cocktail significantly reduces Escherichia coli O157: H7 contamination of lettuce and beef, but does not protect against recontamination. Bacteriophage 2:178-185.

CDC (Centers for Disease Control and Prevention). 2012. Multistate outbreak of listeriosis linked to imported Frescolina Marte brand ricotta salata cheese (Final Update). Accessed Jan. 20, 2019. https://www.cdc.gov/listeria/outbreaks/cheese-09-12/index.html.

CDC (Centers for Disease Control and Prevention). 2013. Multistate outbreak of listeriosis linked to Crave Brothers Farmstead cheeses (Final Update). Accessed Jan. 20, 2019. https://www.cdc.gov/ listeria/outbreaks/cheese-07-13/index.html.

CDC (Centers for Disease Control and Prevention). 2014. Multistate outbreak of listeriosis linked to Roos Foods dairy products (Final Update). Accessed Jan. 20, 2019. https://www.cdc.gov/listeria/ outbreaks/cheese-02-14/index.html.

CDC (Centers for Disease Control and Prevention). 2015. Multistate outbreak of listeriosis linked to soft cheeses distributed by Karoun Dairies, Inc. (Final Update). Accessed Jan. 20, 2019. https://www .cdc.gov/listeria/outbreaks/soft-cheeses-09-15/index.html.

CDC (Centers for Disease Control and Prevention). 2017. Listeria outbreaks. Accessed Jan. 20, 2019. https://www.cdc.gov/listeria/risk .html.

Chibani-Chennoufi, S., A. Bruttin, M. L. Dillmann, and H. Brussow. 2004. Phage-host interaction: An ecological perspective. J. Bacteriol. 186:3677-3686.

Clokie, M. R., A. D. Millard, A. V. Letarov, and S. Heaphy. 2011. Phages in nature. Bacteriophage 1:31-45.

Cotter, P. D., and C. Hill. 2003. Surviving the acid test: Responses of gram-positive bacteria to low pH. Microbiol. Mol. Biol. Rev. $67: 429-453$.

Curtis, G. D. W. W. W. Nichols, and T. J. Falla. 1989. Selective agents for listeria can inhibit their growth. Lett. Appl. Microbiol. $8: 169-172$.

Dalgaard, P., and O. Mejlholm. 2019. Modeling growth of Listeria and lactic acid bacteria in food environments. Pages 247-264 in Foodborne Bacterial Pathogens. Humana Press, New York, NY.

Denes, T., and M. Wiedmann. 2014. Environmental responses and phage susceptibility in foodborne pathogens: Implications for improving applications in food safety. Curr. Opin. Biotechnol. 26:4549

Denes, T., H. C. den Bakker, J. I. Tokman, C. Guldimann, and M. Wiedmann. 2015. Selection and characterization of phage-resistant mutant strains of Listeria monocytogenes reveal host genes linked to phage adsorption. Appl. Environ. Microbiol. 81:4295-4305.

Eugster, M. R., L. S. Morax, V. J. Huls, S. G. Huwiler, A. Leclercq, M. Lecuit, and M. J. Loessner. 2015. Bacteriophage predation promotes serovar diversification in Listeria monocytogenes. Mol. Microbiol. 97:33-46. 
Farkye, N., B. B. Prasad, R. Rossi, and O. R. Noyes. 1995. Sensory and textural properties of queso blanco-type cheese influenced by acid type. J. Dairy Sci. 78:1649-1656.

Fister, S., C. Robben, A. K. Witte, D. Schoder, M. Wagner, and P. Rossmanith. 2016. Influence of environmental factors on phagebacteria interaction and on the efficacy and infectivity of phage P100. Front. Microbiol. 7:1152.

Genigeorgis, C., M. Carniciu, D. Dutulescu, and T. B. Farver. 1991. Growth and survival of Listeria monocytogenes in market cheeses stored at 4 to $30^{\circ} \mathrm{C}$. J. Food Prot. 54:662-668.

Goodridge, L. D., and B. Bisha. 2011. Phage-based biocontrol strategies to reduce foodborne pathogens in foods. Bacteriophage 1:130137.

Guenther, S., D. Huwyler, S. Richard, and M. Loessner. 2009. Virulent bacteriophage for efficient biocontrol of Listeria monocytogenes in ready-to-eat foods. Appl. Environ. Microbiol. 75:93-100.

Guenther, S., and M. J. Loessner. 2011. Bacteriophage biocontrol of Listeria monocytogenes on soft ripened white mold and red-smear cheeses. Bacteriophage 1:94-100.

Guillier, L., V. Stahl, B. Hezard, E. Notz, and R. Briandet. 2008. Modelling the competitive growth between Listeria monocytogenes and biofilm microflora of smear cheese wooden shelves. Int. J. Food Microbiol. 128:51-57.

Hnosko, J., S. Clark, and D. Van Hekken. 2008. Latin American Cheeses. Pages 489-504 in The Sensory Evaluation of Dairy Products. S. Clark, M. Costello, M. Drake, and R. Bodyfelt, ed. Springer, New York, NY.

Holle, M. J., L. A. Ibarra-Sanchez, X. Liu, M. J. Stasiewicz, and M. J. Miller. 2018. Microbial analysis of commercially available US Queso Fresco. J. Dairy Sci. 101:7736-7745.

Ibarra-Sánchez, L. A., M. L. Van Tassell, and M. J. Miller. 2017. Invited review: Hispanic-style cheeses and their association with Listeria monocytogenes. J. Dairy Sci. 100:2421-2432.

Jackson, K. A., L. H. Gould, J. C. Hunter, Z. Kucerova, and B. Jackson. 2018. Listeriosis outbreaks associated with soft cheeses, United States, 1998-2014. Emerg. Infect. Dis. 24:1116-1118.

Jeffers, G. T., J. L. Bruce, P. L. McDonough, J. Scarlett, K. J. Boor, and M. Wiedmann. 2001. Comparative genetic characterization of Listeria monocytogenes isolates from human and animal listeriosis cases. Microbiology 147:1095-1104.

Kabuki, D. Y., A. Y. Kuaye, M. Wiedmann, and K. J. Boor. 2004. Molecular subtyping and tracking of Listeria monocytogenes in Latinstyle fresh-cheese processing plants. J. Dairy Sci. 87:2803-2812.

Kim, J. W., R. M. Siletzky, and S. Kathariou. 2008. Host ranges of Listeria-specific bacteriophages from the turkey processing plant environment in the United States. Appl. Environ. Microbiol. 74:6623-6630.

Klumpp, J., and M. J. Loessner. 2013. Listeria phages: Genomes, evolution, and application. Bacteriophage 3:e26861.

Langlet, J., F. Gaboriaud, and C. Gantzer. 2007. Effects of pH on plaque forming unit counts and aggregation of MS2 bacteriophage. J. Appl. Microbiol. 103:1632-1638.

Lee, S., M. G. Kim, H. S. Lee, S. Heo, M. Kwon, and G. Kim. 2017. Isolation and characterization of Listeria phages for control of growth of Listeria monocytogenes in milk. Korean J. Food Sci. Anim. Resour. 37:320-328.

Leggett, L. N., P. M. Tomasula, D. L. Van Hekken, A. C. S. PortoFett, B. Shoyer, J. A. Renye, J. B. Luchansky, and N. Farkye. 2012. Effect of storage at 4 and $10 \mathrm{C}$ on the growth of Listeria moncytogenes in and on queso fresco. J. Food Saf. 32:236-245.

Lenth, R. V. 2016. Least squares means: The R Package lsmeans. J. Stat. Softw. 69:1-33.

Mahony, J., O. McAuliffe, R. P. Ross, and D. van Sinderen. 2011. Bacteriophages as biocontrol agents of food pathogens. Curr. Opin. Biotechnol. 22:157-163.

Manfreda, G., A. De Cesare, S. Stella, M. Cozzi, and C. Cantoni. 2005. Occurrence and ribotypes of Listeria monocytogenes in Gorgonzola cheeses. Int. J. Food Microbiol. 102:287-293.

Mounier, J., C. Monnet, T. Vallaeys, R. Arditi, A. Sarthou, A. Helias, and F. Irlinger. 2008. Microbial interactions within a cheese microbial community. Appl. Environ. Microbiol. 74:172-181.
Nightingale, K. K., Y. H. Schukken, C. R. Nightingale, E. D. Fortes, A. J. Ho, Z. Her, Y. T. Grohn, P. L. McDonough, and M. Wiedmann. 2004. Ecology and transmission of Listeria monocytogenes infecting ruminants and in the farm environment. Appl. Environ. Microbiol. 70:4458-4467.

Oliveira, M., I. Vinas, P. Colas, M. Anguera, J. Usall, and M. Abadias. 2014. Effectiveness of a bacteriophage in reducing Listeria monocytogenes on fresh-cut fruits and fruit juices. Food Microbiol. 38:137-142.

Orsi, R. H., H. C. den Bakker, and M. Wiedmann. 2011. Listeria monocytogenes lineages: Genomics, evolution, ecology, and phenotypic characteristics. Int. J. Med. Microbiol. 301:79-96.

Østergaard, N. B., A. Eklow, and P. Dalgaard. 2014. Modeling the effect of lactic acid bacteria from starter- and aroma culture growth of Listeria monocytogenes in cottage cheese. Int. J. Food Microbiol. 188:15-25.

Perera, M. N., T. Abuladze, M. Li, J. Woolston, and A. Sulakvelidze. 2015. Bacteriophage cocktail significantly reduces or eliminates Listeria monocytogenes contamination on lettuce, apples, cheese, smoked salmon and frozen foods. Food Microbiol. 52:42-48.

Piffaretti, J. C., H. Kressebuch, M. Aeschbacher, J. Bille, E. Bannerman, J. M. Musser, R. K. Selander, and J. Rocourt. 1989. Genetic characterization of clones of the bacterium Listeria monocytogenes causing epidemic disease. Proc. Natl. Acad. Sci. USA 86:38183822 .

R Core Team. 2015. R: A language and environment for statistical computing. R Foundation for Statistical Computing, Vienna, Austria. http://www.R-project.org/.

Rasmussen, O. F., P. Skouboe, L. Dons, L. Rossen, and J. E. Olsen. 1995. Listeria monocytogenes exists in at least three evolutionary lines: Evidence from flagellin, invasive associated protein and listeriolysin O genes. Microbiology 141:2053-2061.

Roberts, A., K. Nightingale, G. Jeffers, E. Fortes, J. M. Kongo, and M. Wiedmann. 2006. Genetic and phenotypic characterization of Listeria monocytogenes lineage III. Microbiology 152:685-693.

Scallan, E., R. M. Hoekstra, F. J. Angulo, R. V. Tauxe, M. A. Widdowson, S. L. Roy, J. L. Jones, and P. M. Griffin. 2011. Foodborne illness acquired in the United States-major pathogens. Emerg. Infect. Dis. 17:7-15

Sharma, C. S., J. Dhakal, and R. Nannapaneni. 2015. Efficacy of lytic bacteriophage preparation in reducing Salmonella in vitro, on turkey breast cutlets, and on ground turkey. J. Food Prot. $78: 1357-1362$

Silva, E. N., A. C. Figueiredo, F. A. Miranda, and R. C. de Castro Almeida. 2014. Control of Listeria monocytogenes growth in soft cheeses by bacteriophage P100. Braz. J. Microbiol. 45:11-16.

Soni, K. A., M. Desai, A. Oladunjoye, F. Skrobot, and R. Nannapaneni. 2012. Reduction of Listeria monocytogenes in queso fresco cheese by a combination of listericidal and listeriostatic GRAS antimicrobials. Int. J. Food Microbiol. 155:82-88.

Swaminathan, B., D. Cabanes, W. Zhang, and P. Cossart. 2007. Listeria monocytogenes. in Food Microbiology: Fundamentals and Frontiers. 3rd ed. American Society of Microbiology, Washington, DC.

Takahashi, H., K. Takada, T. Tsuchiya, S. Miya, T. Kuda, and B. Kimura. 2015. Listeria monocytogenes develops no resistance to ferulic acid after exposure to low concentrations. Food Control $47: 560-563$

Tirloni, E., S. Stella, C. Bernardi, P. Dalgaard, and P. S. Rosshaug. 2019. Predicting growth of Listeria monocytogenes in fresh ricotta. Food Microbiol. 78:123-133.

Tokman, J. I., D. J. Kent, M. Wiedmann, and T. Denes. 2016. Temperature significantly affects the plaquing and adsorption efficiencies of Listeria phages. Front. Microbiol. 7:631.

Trmčić, A., R. Ralyea, L. Meunier-Goddik, C. Donnelly, K. Glass, D. D’Amico, E. Meredith. M. Kehler, N. Tranchina, C. McCue, and M. Wiedmann. 2017. Consensus categorization of cheese based on water activity and $\mathrm{pH}-\mathrm{A}$ rational approach to systemizing cheese diversity. J. Dairy Sci. 100:841-847.

Uhlich, G. A., J. B. Luchansky, M. L. Tamplin, F. J. Molina-Corral, S. Anandan, and A. C. S. Porto-Fett. 2006. Effect of storage tem- 
perature on the growth of Listeria monocytogenes on queso blanco slices. J. Food Saf. 26:202-214.

Van Hekken, D. L., M. H. Tunick, J. A. Renye Jr., and P. M. Tomasula. 2017. Characterization of starter-free Queso Fresco made with sodium-potassium salt blends over 12 weeks of 4 degrees C storage. J. Dairy Sci. 100:5153-5166.

Van Tassell, M. L., L. A. Ibarra-Sanchez, S. R. Takhar, S. L. AmayaLlano, and M. J. Miller. 2015. Use of a minature fresh cheese model for investigating antimicrobial activities. J. Dairy Sci. 98:8515-8524.

Verheul, A., N. J. Russell, T. H. R. Van, F. M. Rombouts, and T. Abee. 1997. Modifications of membrane phospholipid composition in nisin-resistant Listeria monocytogenes Scott A. Appl. Environ. Microbiol. 63:3451-3457.

Vongkamjan, K., A. M. Switt, H. C. den Bakker, E. D. Fortes, and M. Wiedmann. 2012. Silage collected from dairy farms harbors an abundance of listeriaphages with considerable host range and genome size diversity. Appl. Environ. Microbiol. 78:8666-8675.

Ward, T. J., T. F. Ducey, T. Usgaard, K. A. Dunn, and J. P. Bielawski. 2008. Multilocus genotyping assays for single nucleotide polymorphism-based subtyping of Listeria monocytogenes isolates. Appl. Environ. Microbiol. 74:7629-7642.

Wendlinger, G., M. J. Loessner, and S. Scherer. 1996. Bacteriophage receptors on Listeria monocytogenes cells are the N-acetylglucosamine and rhamnose substituents of teichoic acids or the peptidoglycan itself. Microbiology 142:985-992.

Wiedmann, M., J. L. Bruce, C. Keating, A. E. Johnson, P. L. McDonough, and C. A. Batt. 1997. Ribotypes and virulence gene polymorphisms suggest three distinct Listeria monocytogenes lineages with differences in pathogenic potential. Infect. Immun. $65: 2707-2716$ 